\title{
Article
}

\section{Digital Marketing of Commercial Complementary Foods in Australia: An Analysis of Brand Messaging}

\author{
Trish Dearlove, Andrea Begley $(\mathbb{D}$, Jane Anne Scott $(\mathbb{D}$ and Gemma Devenish-Coleman *(D) \\ School of Population Health, Curtin University, Perth 6102, Australia; \\ patricia.dearlove@postgrad.curtin.edu.au (T.D.); a.begley@curtin.edu.au (A.B.); jane.scott@curtin.edu.au (J.A.S.) \\ * Correspondence: gemma.devenish@curtin.edu.au; Tel.: +61-8-92667497
}

Citation: Dearlove, T.; Begley, A.; Scott, J.A.; Devenish-Coleman, G. Digital Marketing of Commercial Complementary Foods in Australia: An Analysis of Brand Messaging. Int. J. Environ. Res. Public Health 2021, 18, 7934. https://doi.org/10.3390/ ijerph18157934

Academic Editors: Nikki

Ann Boswell, Rebecca Byrne,

Ruth Newby, Paulina Nowicka and Emma Haycraft

Received: 17 June 2021

Accepted: 19 July 2021

Published: 27 July 2021

Publisher's Note: MDPI stays neutral with regard to jurisdictional claims in published maps and institutional affiliations.

Copyright: (c) 2021 by the authors. Licensee MDPI, Basel, Switzerland. This article is an open access article distributed under the terms and conditions of the Creative Commons Attribution (CC BY) license (https:// creativecommons.org/licenses/by/ $4.0 /)$.

\begin{abstract}
The digital marketing of commercial complementary foods (CCF) is an emerging area of concern in Australia. Although research into traditional methods has identified a range of problems, the marketing and messaging strategies employed within digital spaces have gone largely unscrutinized. This study sought to examine the methods used by CCF manufacturers to promote Australian baby foods and brands in a digital space. A multiple step approach was used to assess the CCF brands available in major Australian retailers, the social media platforms they used, and to thematically analyze the text and visual messages contained in posts published over a three-month period. Of the 15 brands identified, 12 had a digital presence, and all of these used Facebook. Four themes emerged from an analysis of 216 Facebook posts; (1) general product attributes, (2) socially desirable attributes (which included messaging related to taste $(41 \%)$, self-feeding $(29 \%)$ and fun $(19 \%))$, (3) concern-based attributes (including organic status $(40 \%)$, age targets (39\%) and additive/allergen-free status (18\%)) and (4) health-focused attributes (which included messaging related to healthy/nutritious ingredients (45\%), and child development/growth (15\%). Messages contained in Facebook posts were mostly positive brand/product aspects (Themes 1 and 2) or parental concernbased aspects (Theme 3 and 4). These themes match previous analyses of marketing content in traditional media and should be closely monitored due to the personalized nature of consumer social media interactions.
\end{abstract}

Keywords: digital advertising; baby foods; complementary feeding; infant feeding; food marketing; online; promotion

\section{Introduction}

The importance of early life nutrition is well recognised in the development of later health outcomes, yet in Australia there are few regulations or policies that address infant and young child feeding (IYCF) practices other than breastfeeding [1-3]. The World Health Organization (WHO) Resolution on Ending the Inappropriate Promotion of Foods for Infants and Young Children provides recommendations to support optimal IYCF practices [4] however these are poorly implemented in Australia [5]. The Marketing in Australia of Infant Formulas: Manufacturers and Importers Agreement (MAIF) is focused exclusively on regulating infant and follow on formulas, which in Australia are those suitable from birth to 12 months of age [6]. Developed in response to the WHO International Code of Marketing of Breastmilk Substitutes, the MAIF agreement is self-regulated by signatories who have been criticized for their refusal to include toddler milks-formula-like milk products for children 12 months and above-and complementary foods as part of this agreement [6,7]. Additionally, while the 2019 National Breastfeeding Strategy details some recommendations for improvements in IYCF practices, they are few and poorly supported by practical policy or legislation [8]. Critically, much of the development of policy and recommendations is focused on breastfeeding and breast milk substitutes, including toddler milks, which leaves complementary feeding unscrutinized. 
Complementary foods (CF), which are those first foods given to babies and toddlers alongside continued breastfeeding or infant formula, are recommended to be timely, adequate, safe and appropriate [4]. The WHO emphasizes the importance of CF being home prepared using nutrient-rich, locally available foods and advises not to introduce $\mathrm{CF}$ before six months of age [4]. In Australia, early introduction of solid foods is an issue, with approx. $35 \%$ of babies receiving solid food at 4 months of age and $92 \%$ by 6 months of age [9]. Recent research has highlighted the problematic nature of commercial complementary foods (CCF) which disregard the WHO recommendations across each of the four domains;

- Timely-CCF packaging that implies suitability for infants under 6 months [10];

- Adequate-high added sugar content and generally low nutrient density of CCF render them inappropriate for the needs of infants [11,12];

- Safe-ready-to-eat CCF products are not sterile once opened and pose a risk if leftovers are not stored correctly, additionally, squeeze pouch caps pose a choking hazard [10];

- Appropriate-CCF from squeeze pouches delivers food via a sucking motion which, in excess, may hinder oral skill development [10]. Additionally, the smooth-puree texture of most ready-to-eat $\mathrm{CCF}$ is at odds with texture progression recommendations to aim for family foods by 12 months of age [13].

In recent years there has been a dramatic increase in the number of CCF available for purchase in Australia [14], including those designed as first solids through ready-to-eat meals in various packaging formats, to snack foods for toddlers and young children, as well as a rise in the marketing of these products. Many snacks marketed to infants and toddlers are classified as discretionary foods-energy dense, nutrient poor foods not recommended as part of a healthy diet for infants and young children [3,15].

Traditional media sources of advertising CCF and breast milk substitutes such as parenting magazines have been the subject of past research, while newer forms such as digital marketing are a more recent area of study. Research has centred on breast milk substitute promotion as well as the direct targeting of children and adolescents by the food industry [16-22]. Social media is emerging as an area of much concern in marketing due to the personalized nature of platforms which offer targeted content direct to consumers [23]. This personalized content, where ads appear to individuals based on previous buying or viewing history, has been associated with increased brand awareness and ad credibility as well as a reduced resistance to the ad [24]. Australians are enthusiastic users of social media- $60 \%$ of the total population are active users on Facebook, half use YouTube and $35 \%$ of Australians are on Instagram [25]. Digital marketing has been embraced by industry as a means to shape parental perceptions and the social norms for IYCF [20,26], positioning their brands as providers of sympathetic support [23]. This is achieved by the extensive consumer research that goes into understanding the desires and drivers of parenting attitudes, allowing corporations to profile consumers and market brands that are targeted to appeal to the aspirations of the parents [23]. Parents have long been recognised as gatekeepers of children's nutrition, yet the assumption that parents are able to determine what constitutes healthy eating behaviors is flawed [27]. The huge volume of marketing and mass media content leads to information fatigue and the disregarding of evidencebased nutrition advice from health professionals, which is seen as merely another opinion, less valued than the views of peers and family [27-29]. It is necessary, therefore, to understand what is being said to parents through marketing in order to combat the norms CCF manufacturers are trying to influence and the impact on IYCF this may have [30].

This study sought to understand what methods are being used by manufacturers of non-perishable CCF available in Australia to promote baby food brands and products in a digital space. The objectives were: to identify the CCF brands available in major Australian retailers and the digital media advertising platforms they use; to identify what the stated marketing messages present on selected social media are; and to determine what implicit messages are being conveyed by text and imagery of these sites to promote CCF. 


\section{Materials and Methods}

A multiple step approach was used to obtain a three-month snapshot of explicit and implicit marketing messages.

\subsection{Brand Audit}

A brand audit identified CCF brands available for purchase in leading Western Australian supermarkets and pharmacies by searching the 'baby food' category of retailer websites. These are the shelf stable, bagged, boxed and jar foods typically displayed in the baby aisle of supermarkets and pharmacies alongside breastmilk substitutes. Coles and Woolworths, the two major supermarket chains in Australia, represent more than $67 \%$ of the Australian baby food retail market [14], thus were deemed suitably representative of the range of brands available. A Google search of pharmacies was conducted to determine if there were significant brands available by ordering online from these retailers. It was found that a majority of pharmacies carry few, if any, CCF products. Chemist Warehouse was the only exception, therefore this retailer was also included. No product age range was used (e.g., 0-12 months, 2+ years) as the products observed either had only a minimum age rather than a range (e.g., suitable from 8 months) or offer no age recommendation at all. While food for young children may be considered as designed for those under three years of age, it should be noted that there is no restriction preventing their consumption by, or promotion to older children.

The number and type of unique non-perishable CCF products available at each outlet was recorded from the retailer websites. Products were classified into four categories and five sub-categories; ready-to-eat meals (subdivided by packaging format: jar, squeeze pouch, larger pouch), ready-to-prepare foods (for example porridge and rice cereal), readyto-cook (for example dry pasta) and ready-to-eat snack (subdivided into teething rusks or older baby/toddler snack). Infant formula and toddler milks were not included in this study. The number of CCF products available from each retailer for each brand was calculated as a total and by product type, and the relative market share of each brand was determined.

\subsection{Websites and Social Media-Quantitative Analysis}

Brands that did not have a website or social media account were retained in the brand audit reporting, but were ineligible for the remaining analyses. Where available, Australian websites were located by a Google search to imitate consumer behaviour. Descriptive data were collected from these websites, including links to brand social media accounts. Facebook was chosen as the social media platform to be investigated due to its use by all brands, as well as having the highest number of users in Australia [25]. The number of likes and followers of each brand's Facebook page were recorded, along with the total number of posts published in the preceding three months (10 June-11 September 2020). This was used to calculate the mean monthly posting rate for each brand. Due to the transient nature of information in online spaces, all posts in this period were captured using screenshots for thematic analysis.

\subsection{Facebook-Qualitative Analysis}

The marketing messages presented via Facebook posts by CCF manufacturers were thematically coded using a deductive approach. The first author (TD) developed the codebook and coded all data. Comments and other user generated content were excluded from coding unless they were reposted by the page administrator, i.e., only content that was created by the brand was coded. Hashtags were also excluded. A set of initial codes were identified a priori, based on prior research of traditional media [31,32], and preliminary researcher observations. These codes were then piloted using the first month's posts (capped at 10) for each brand. During this stage, the code descriptions were refined, and additional codes were identified and added. This set was then used to code all Facebook posts that had been captured for each brand. A multiple-pass process was followed for 
each post. Firstly, the text of each post was reviewed for relevant keywords and an initial set of codes assigned. Secondly, any accompanying images were reviewed for messages not inherent in the post text. A final text review confirmed the code selection and identified any additional messages not initially noted. Posts were assigned as many codes as were applicable. During this process any messaging that did not fit the code categories were noted. Scrutiny of these notes resulted in the development of six further code categories and all data were analysed a second time. The final list of codes and their descriptions are presented in Supplementary Table S1.

A second coder $(\mathrm{AB})$ independently assigned codes to a sub-sample to assess bias. Inter-coder reliability was calculated using simple percent agreement of a sample of 20 posts selected by random number generation. Across the 20 posts, 233 codes were assigned, of which $210(90.1 \%)$ were in agreement. Discrepancies were assessed independently by a third reviewer (GDC) and discrepant codes discussed and then consensually coded. Codes were then assessed for frequency and grouped into themes. Additionally, each post was assigned to one of seven categories based on content type (product range, broad values, social/parenting support, incentives, informative, engagement/connection building, expert/celebrity endorsement), descriptions of which are presented in Supplementary Table S2. All data coding and analysis were performed in Microsoft Excel (Microsoft, Albuquerque, NM, USA).

\section{Results}

Across the 15 brands identified in the brand audit, there were 210 unique CCF lines in Coles, with smaller product ranges found in Woolworths and Chemist Warehouse (Table 1). No category of product was represented by all brands, though most produced products in the ready-to-eat categories, both meals and snacks, which were the most numerous product types, comprising over $80 \%$ of products sold in Chemist Warehouse and more than $90 \%$ of products in Woolworths and Coles. Ready-to-eat meals packaged in jars were exclusive to the Heinz brand and not found in Chemist Warehouse, while ready-to-cook baby foods, exclusive to Bellamy's Organic brand were only found in Chemist Warehouse.

Table 1. Commercial complementary food lines by category per outlet.

\begin{tabular}{cccc}
\hline & \multicolumn{2}{c}{ Unique Commercial Complementary Food Lines } \\
\hline & Coles & Woolworths & Chemist Warehouse \\
& 210 & 147 & 129 \\
\hline Product Category & \multicolumn{3}{c}{ Proportion (\%) } \\
\hline Ready-to-eat Meal & 55 & 69 & 53 \\
Jar & 5 & 9 & 0 \\
Larger Pouch & 7 & 12 & 2 \\
Squeeze Pouch & 43 & 48 & 15 \\
Ready-to-prepare (Cereal) & 4 & 6 & 3 \\
Ready-to-cook (Dry Pasta) & 0 & 0 & 29 \\
Ready-to-eat Snack & 41 & 25 & 6 \\
First foods (Rusks) & 3 & 5 & 23 \\
Older Baby/Toddler Snack & 38 & 20 & \\
\hline
\end{tabular}

Brands differed in the range of products offered across the retailers, with no outlet carrying all 15 brands. Table 2 shows the presence of each brand in each retailer. Major brands across all three outlets included Rafferty's Garden (22-25\% product range share), Heinz/Farex (16-20\%) and Bellamy's Organic (7-23\%). Only Organic (13-18\%) and Bellies $(9-16 \%)$ were prominent in supermarkets, while Bubs Organics had a strong presence in the pharmacy chain $(17 \%)$. 
Table 2. Brand presence of commercial complementary foods (market share by product lines) in Coles Supermarkets, Woolworths Supermarkets and Chemist Warehouse Pharmacy.

\begin{tabular}{cccc}
\hline Brand & \multicolumn{3}{c}{ Product Lines, $\boldsymbol{n} \mathbf{( \% )}$} \\
\hline Coles & Woolworths & Pharmacies \\
\hline Bellies & $20(9)$ & $23(16)$ & - \\
Baby Mum Mum & $4(2)$ & $3(2)$ & $5(4)$ \\
Bellamy's Organic & $14(7)$ & $13(9)$ & $30(23)$ \\
Bubs Organics & $7(3)$ & - & $22(17)$ \\
CUB & $14(7)$ & - & - \\
Farex & $2(1)$ & $4(3)$ & $5(4)$ \\
Heinz & $31(15)$ & $25(17)$ & $15(12)$ \\
Kiddylicious & $12(6)$ & $2(1)$ & - \\
Little Quacker & $4(2)$ & $1(1)$ & $9(7)$ \\
Macro & - & $11(7)$ & - \\
Nestle Cerelac & $5(2)$ & $3(2)$ & $4(3)$ \\
Only Organic & $38(18)$ & $19(13)$ & - \\
Rafferty's Garden & $52(25)$ & $32(22)$ & $29(22)$ \\
Whole Kids & $7(3)$ & $2(1)$ & - \\
Smiling Tums & - & $9(6)$ & $129(100)$ \\
Total & $210(100)$ & $147(100)$ &
\end{tabular}

Of the 15 brands identified, 12 were found to have a website presence. One website featured two of these brands (Farex, owned by Heinz), so a total of 11 websites were investigated in the remaining analyses. The brands that did not have a website were all supermarket brands (Macro, Smiling Tums, CUB). Facebook ( $n=11,100 \%)$ and Instagram $(n=9,82 \%)$ were the most common social media accounts linked to the brand websites, with YouTube $(n=4,36 \%)$, Twitter $(n=2,18 \%)$ and WeChat $(n=1,9 \%)$ the other social media platforms used (Table 3 ).

Table 3. Facebook posts by commercial complementary food brand pages, 10 June-11 September 2020.

\begin{tabular}{|c|c|c|c|c|}
\hline \multirow[t]{2}{*}{ Brand } & \multirow{2}{*}{$\begin{array}{c}\text { Page Followers/Page } \\
\text { Likes * }\end{array}$} & \multicolumn{2}{|c|}{ Number of Posts } & \multirow{2}{*}{$\begin{array}{c}\text { Most Common Post Type } \\
\text { (Number Across All } \\
\text { Months) }\end{array}$} \\
\hline & & Average per Month & Total of 3 Months & \\
\hline Bellies & $7198 / 7022$ & 14.33 & 43 & Product Range $(n=19)$ \\
\hline Baby Mum Mum & $19,649 / 19,834$ & 2 & 6 & Incentive $(n=4)$ \\
\hline Bellamy's Organic & $156,377 / 157,564$ & 4.3 & 13 & Product Range $(n=8)$ \\
\hline Bubs Organic & $85,466 / 85,199$ & 12 & 36 & Product Range $(n=25)$ \\
\hline Heinz & $48,105 / 48,780$ & 0 & 0 & - \\
\hline Kiddylicious & $11,748 / 11,736$ & 8.3 & 25 & Product Range $(n=17)$ \\
\hline Little Quacker & $3083 / 3088$ & 0.33 & 1 & Product Range $(n=1)$ \\
\hline Nestle & $20,435 / 20,642$ & 2 & 6 & Support $(n=5)$ \\
\hline Only Organic & $31,783 / 32,491$ & 6.67 & 20 & Product Range $(n=11)$ \\
\hline Rafferty's Garden & $58,905 / 59,316$ & 6.33 & 19 & Product Range $(n=9)$ \\
\hline Whole Kids & $30,350 / 30,234$ & 16 & 48 & Engagement $(n=17)$ \\
\hline
\end{tabular}

${ }^{*}$ Number of page followers and likes as at 12 September 2020.

Facebook page followers and likes were very variable but did not appear related to posting frequency in this measurement period. A total of 216 posts were captured across 10 brand pages, with Heinz the only brand to not produce any social media content in the monitoring period. Product range was the most common post type for 7 of the 11 brands and comprised nearly half of all post types (Table 4). Brand image building posts were also frequently evident in the form of content about broad company values $(14.8 \%)$ and posts that sought engagement or connection with parents (14.8\%). Incentives (that is, giveaways, competitions or other prize giving opportunities) comprised $10.6 \%$ of all brand posts but 
were the single most common post type for Baby Mum Mum (66\% of Baby Mum Mum posts). With the exception of one Father's Day engagement piece, all posts by Nestle $(n=5)$ referred consumers to their website, while other brands used this technique on average one in every ten posts.

Table 4. Commercial complementary food brands' Facebook post categories, marketing message themes and marketing message categories.

\begin{tabular}{|c|c|}
\hline & Total Posts All Brands, $n(\%)$ \\
\hline \multicolumn{2}{|l|}{ Post Content Category } \\
\hline Product Range & $104(48.1)$ \\
\hline Broad Values & $32(14.8)$ \\
\hline Incentives & $23(10.6)$ \\
\hline Social/Parenting Support & $11(5.1)$ \\
\hline Engagement/Connection Building & $32(14.8)$ \\
\hline Expert/Celebrity Endorsement & $10(4.6)$ \\
\hline Informative & $4(1.9)$ \\
\hline Total & 216 \\
\hline \multicolumn{2}{|c|}{ Marketing Message Themes and Categories } \\
\hline \multicolumn{2}{|l|}{ Theme 1-General Product Attributes } \\
\hline Taste/Flavor & $89(41.2)$ \\
\hline Texture & $36(16.7)$ \\
\hline New product & $29(13.4)$ \\
\hline \multicolumn{2}{|l|}{ Theme 2-Socially Desirable Attributes } \\
\hline Self-Feeding & $63(29.2)$ \\
\hline Fun/Positive Experience & $41(18.9)$ \\
\hline Solution to a Problem & $31(14.4)$ \\
\hline Australian made/owned & $11(5.1)$ \\
\hline Happy Children Images & $104(48.1)$ \\
\hline \multicolumn{2}{|l|}{ Theme 3-Concern-based Attributes } \\
\hline Organic & $86(39.8)$ \\
\hline Additive/Allergen Free & $39(18.1)$ \\
\hline Referring to Child Age & $84(38.9)$ \\
\hline \multicolumn{2}{|l|}{ Theme 4-Health-focused Attributes } \\
\hline Child Development/Growth & $32(14.8)$ \\
\hline Health Support/Healthy Habit & $17(7.9)$ \\
\hline Healthy Ingredients/Nutrition & $98(45.4)$ \\
\hline
\end{tabular}

Three of the 11 brands are also manufacturers of formula and toddler milk products, with only Nestle not featuring milks, nor any branded product, in their Facebook posts. Both Bubs Organics and Bellamy's Organic promoted toddler milks heavily in their posts and both were the only brands to utilize celebrity endorsement. The use of endorsement by celebrities or experts was found in less than $5 \%$ of total posts; this technique was utilized by only three brands. A quarter of Bellies posts contained the advice of their 'natural feeding expert' to promote their ready-to-eat snacks.

As shown in Table 4, positive images of babies and children appeared in almost half of all posts (48.1\%). Messages around taste/flavor, organic status of products, self-feeding and healthy/nutritious ingredients also featured heavily in posts, often in combination. About $40 \%$ of posts $(n=84)$ contained messaging about a specific age target, usually a "suitable from $x$ months" for the product. The appearance of packaging with the " $4+$ months" occurred in nine of the 216 posts, with all ready-to-eat snack food products carrying a minimum age of $6+$ months. Bubs Organics was the only brand to specifically target an older child age range with their junior nutrition drink recommended for ages 3-12 years, although images of school-aged children were used by several brands.

Four themes emerged from the marketing messages of the Facebook posts: general product attributes, socially desirable attributes, concern-based attributes and healthfocused attributes. General product attributes incorporated messages that made the prod- 
uct sound appetizing, around texture- "new texture adventures", and taste- "yummy new flavors" as well as promoting novel products (e.g., mini yoghurt drops). Socially desirable attributes were the social ideals that promote fun and positivity for the child- "make snack time fun", or ease for the parent in the form of a solution to a perceived problem"soothe those teething troubles", or promotion of self -feeding which has a dual role in being convenient for parents as well as popular within the 'baby-led weaning' approach The promotion of Australian made or owned via use of 'local' suppliers or 'Aussie mum and dad' created businesses was also considered a social ideal message, as was positive imagery of babies and children. Concern-based attributes included those designed to appeal to a particular kind of consumer need such as organic ingredients, or the absence of allergens or additives-"free from GMOs, chemicals and preservatives", for parents who value these. Health-focused attributes were the messages that target parental desires to ensure the health of children, through supporting growth and development- "grow up strong" and "encourage ... tongue lateralization", assisting health-"support their immune system" or developing healthy habits-"foster a healthy relationship with food", as well as the promotion of healthy ingredients, specific nutrients and the nutritious quality of products-"premium nutrition enriched with prebiotics and probiotics". A detailed list of messages and the type of product it promotes can be found in Supplementary Table S3. Broadly, messaging may be considered as falling into one of two domains; to either promote some aspect of the product deemed as desirable or to capitalize on some aspect of parental concern.

\section{Discussion}

This study investigated the baby food brands available in major Australian retailers, the social media advertising platforms they use, and the messages conveyed via language and imagery to promote CCFs in Australia. Facebook is utilized by Australian CCF manufacturers to build positive brand perceptions through posts designed to be emotionally engaging and supportive as well as tactics such as endorsements by celebrities or experts, competitions and giveaways. This positive branding also encompasses promotion of specific brand values and products. The four themes that emerged from the content analysis of messages published in Facebook posts can be seen as encompassing two domains. First, desirable attributes like taste, texture and self-feeding. Second, parental concerns targeting health, development, allergens, additives and organic ingredients, which may be thought of as fear-based drivers. While marketing of a brand or product's desirable attributes is an expected advertising practice, the fear-based aspect is of concern due to the potential to promote misleading or unrealistic expectations regarding infant feeding.

The effect of CCF marketing on consumer attitudes and behaviour is an area of concern, particularly via digital platforms which allow personalized, targeted advertising direct to parents and caregivers [33,34]. A 2020 systematic review of qualitative research regarding parent perceptions of infant feeding showed "beliefs, values, and perceived norms were a central influence on complementary feeding practices" [35]. The impact of such messaging that targets parental concerns such as fear of choking have been detailed in recent qualitative studies. An investigation of Australian mothers understanding of infant feeding found that although some mothers expressed guilt about using CCF, specific characteristics such as being organic increased the acceptability of these products [28]. For some mothers, CCF were considered safer than home-made foods because the Mothers lacked confidence in their own ability to prepare foods to the correct texture and amount, with age recommendations on CCF packaging viewed as most likely to be texturally appropriate, and therefore safe from choking [28]. Marketing messages reviewed by this study demonstrate that manufacturers are building their marketing around these concerns; promoting the 'benefit' of organic foods and smooth purees, or snacks "designed for little hands" to encourage self-feeding. This tactical marketing has the potential to direct parents away from home prepared foods, undermining confidence of parents and promoting confusion regarding the optimal age for introduction of solids [28]. 
Health consciousness, fueled by targeted marketing of infant nutritional needs is noted by industry as a key driver of market growth [14]. Marketing to a health conscious audience is evident in health-focused theme of this study, and also plays to parental concerns. The awareness of health as a priority for consumers extends past the promotion of healthy ingredients like fruits and vegetables, to claims of broader benefits that products help "foster a healthy relationship with food". Similar to the marketing of toddler milks in Australia and the US [33], the highlighting of nutritious content in CCF-such as vitamins and minerals, pre and probiotics, dietary fibre, omega 6-may result in a 'health halo' effect [33] that leads to parents attaching benefits to these products that may not exist. Furthermore, it has been suggested that this type of marketing may diminish the value of home meals and work to persuade parents that costly commercial foods are essential [33]. Recent research on the nutritional and textural composition of CCF available for sale in Australia demonstrates their unsuitability as a primary food source, being predominantly sweet flavored, low in iron, snack foods that would be classified as noncore, or discretionary items, and purees lacking appropriate textural variety $[15,36]$. The importance of texture in the development of skills is utilized in marketing by brands promoting the value of their snack products in self-feeding and of attributes such as "tongue lateralization", which encourages the perception that these products are necessary for optimal child development. Normalization of manufactured snack foods within the diet, whether they are classified as discretionary foods or not, may encourage high intakes of energy-dense snack foods in later life [15].

In Australia, health and nutrition content claims are prohibited from use for infant formula products, both packaging and advertising, under FSANZ Standard 1.2.7 [19]. It is recommended that this be extended to include infant foods and growing up milks, or any food specifically targeted at children. Additionally, the restriction of health halo statements is advisable. Further, FSANZ Standard 2.9.2-7 specifies that "The label on a package of food for infants must not include a recommendation, whether express or implied, that the food is suitable for infants under the age of 4 months" [2]. No clear breach of this policy was found in the marketing material studied. However, marketing of products as suitable 'first foods' without specifying from age 6 months, as well as packaging indicating suitability from 4 months of age promotes confusion around appropriate timing of introducing solids. The absence of a clear FSANZ guideline prohibiting the promotion of foods for infants under 6 months of age undermines current WHO and health professional guidelines. Promotion of CCF products as suitable for infants from 4 months of age, as observed in this study, should be prohibited given the negative effects of early introduction of CCF [37].

Not only does digital marketing by Australian CCF brands normalize and encourage the use of CCF products, it also promotes toddler milks-formula-like products designed for children over 12 months of age-as necessary for the growth and development of children. Numerous studies have shown that consumers do not differentiate between these toddler milks and infant formula, which in Australia is prohibited from advertising under the industry self-regulated MAIF Code [6,38-40]. As well as the concern that these products act as proxy advertising for infant formula, the promotion of toddler milks themselves is cause for concern given their expense and associations with overweight and obesity in later life [33].

It has been reported that parents describe infant feeding advice from healthcare practitioners as conflicting or frequently changing [28]. Parents want "factual education related to their individual and personal infant feeding choices, provided with sensitivity, in a non-judgmental manner" [35]. This is what social media marketing of CCF is able to offer parents. Digital marketing is designed to provide tailored content; extensive data collection, combined with sophisticated profiling technology allows for identification of patterns of behaviour that can predict and seemingly anticipate the needs and desires of users [41]. Social media networks provide a platform to facilitate data collection and brand engagement, with incentives like competitions and giveaways, as used by CCF manufacturers here, prompting individuals to create and share promotional content of 
their own [41]. Large numbers of people are willing to allow corporations into their social networks, providing free advertising for these companies [42]. Research clearly details the potential harms of digital marketing to children and adolescents, noting that even when young users recognise the attempt to influence them, they may still fail to understand and combat its effects [41]. It may be argued that parents constitute a similarly vulnerable population, due to the desire for the best for their child, and the fear of failing to provide this [43].

The use of emotive messaging in advertising is a longstanding marketing tactic. Emotional advertising is designed to increase the likelihood of the desired reaction-often the purchase- and can be used to foster feelings of vulnerability in the target audience [43]. Investigations of food and beverage marketing found that individuals were 2.5 times more likely to prefer brands whose Facebook posts they had a strong positive reaction to [42]. It is clear that Australian CCF brands are playing to this vulnerability, given the content of posts frequently includes aspects designed to be emotionally engaging and featuring desirable attributes of the brand and products. As explained by the theoretical Elaboration Likelihood Model, the combination of logic-driven promotion of positive aspects and imagery of happy, smiling children designed to evoke an emotional response has been seen in previous studies of traditional media sources and is thought to encourage use of the product [31]. Additionally, the effect of emotive messaging to provoke guilt or fear has been identified as a powerful motivator in advertising to parents [43]. These emotional prompts are visible in much of the content of this study. Socially desirable aspects such as self-feeding and making mealtimes a fun experience may be designed to elicit guilt in parents who feel pressure to perform these behaviors. Fear is also used in messaging around products being 'safe' - particularly with the organic status of foods and promoting fear of additives, pesticides and allergens. Messaging contained in these posts frequently conveys the idea that CCF products are safer, normal and necessary for daily consumption. The relatively unregulated space of digital marketing, particularly social media sites, should be carefully monitored to limit the normalization of reliance on suboptimal practices and CCF products.

This study is not without limitations. The complexity of metrics that control visibility of posts in Facebook news-feeds mean it is not possible to determine what proportion of followers viewed individual posts. The high variability in the number of interactions with similar posts by the same brand indicates that there is wide variation in the number of posts that followers are seeing. Pages are also able to pay for posts to be seen by users who do not follow the page, as well as appearing in feeds of friends of followers, meaning the reach of this marketing is not able to be accurately measured [42]. In addition, results must be considered in light of the events of the coronavirus disease 2019 (Covid-19) pandemic and the subsequent shift in business priorities for many organizations, which may have resulted in the data collection not reflecting the same frequency or content priorities of pre-pandemic times. Furthermore, it is possible that posts or comments may have been removed or altered before or after the point of data collection. Future research in this area is warranted to investigate the impact of these marketing messages and different approaches by brands on parental attitudes. The effect of post format-whether text, image, video or combinations - on message impact may also be an area of interest.

\section{Conclusions}

In Australia, CCF manufacturers utilize social media, predominantly Facebook and Instagram, to promote their brands and products to consumers. Messaging in these communications focuses primarily on positive brand or product attributes such as taste, texture, novelty, self-feeding and solutions to perceived problems; or capitalizing on common parent concerns about organic status of foods, additives and allergens, appropriate texture for age, child development and health. The common strategy of highlighting healthy ingredients and nutrients may create a 'health halo' effect and lead parents to mistakenly believe that these products are necessary and preferable to home-prepared foods. The promotion of 
CCF as suitable for infants under the age of 6 months contravenes WHO recommendations but not FSANZ Standards. It is advisable that these Standards be reviewed to align with the extensive body of evidence that underpins the WHO recommendations. Restriction of both 'health halo' messaging and the promotion of toddler milks is also recommended, given the potential impact on parental perceptions of optimal infant feeding.

Supplementary Materials: The following are available online at https: / www.mdpi.com/article / 10.3390/ijerph18157934/s1, Table S1: Definitions of Code Categories Used to Analyze Commercial Complementary Food Brands Facebook Post Messages, Table S2: Definitions of Categories Used to Assess Commercial Complementary Food Brands Facebook Post Aims, Table S3: Example Messages and Product Promoted by Commercial Complementary Food Brands in Facebook Posts by Coding Attribute.

Author Contributions: Conceptualization, G.D.-C., J.A.S. and A.B.; methodology, G.D.-C. and T.D.; validation, G.D.-C. and A.B.; formal analysis, T.D. and A.B.; investigation, T.D.; data curation, T.D.; writing-original draft preparation, T.D.; writing-review and editing, all authors; supervision, G.D.-C. and A.B.; project administration, T.D. and G.D.-C. All authors have read and agreed to the published version of the manuscript.

Funding: This research received no external funding.

Institutional Review Board Statement: Not applicable.

Informed Consent Statement: Not applicable.

Data Availability Statement: The data presented in this study are available on request from the corresponding author.

Conflicts of Interest: The authors declare no conflict of interest.

\section{References}

1. World Breastfeeding Trends Initiative. WBTi World Ranking: Where Nations Stand? Available online: https://www. worldbreastfeedingtrends.org/wbti-country-ranking.php (accessed on 10 October 2020).

2. Food Standards Australia and New Zealand. Food Standards Code. Available online: https://www.foodstandards.gov.au/code/ Pages / default.aspx (accessed on 3 September 2020).

3. National Health and Medical Research Council. Infant Feeding Guidelines; National Health and Medical Research Council: Canberra, Australia, 2012.

4. World Health Organization. Guidance on Ending the Inappropriate Promotion of Foods for Infants and Young Children: Implementation Manual. Available online: https://apps.who.int/nutrition/publications/infantfeeding/manual-endinginappropriate-promotion-food/en/index.html (accessed on 3 September 2020).

5. World Breastfeeding Trends Initiative Australia. Australia: Report Card 2018. Available online: https://wbtiaus.files.wordpress. com/2018/05/wbti_report_card-australia.pdf (accessed on 3 September 2020).

6. Australian Government. Marketing in Australia of Infant Formulas: Manufacturers and Importers Agreement-The MAIF Agreement. Available online: https://www.accc.gov.au/system/files/public-registers/documents/D15\%2B143530.pdf (accessed on 3 September 2020).

7. Browne, K. Do Toddlers Need Their Own Milk? Available online: https://www.choice.com.au/babies-and-kids/feedingchildren/making-healthy-choices/articles/are-toddler-formulas-just-marketing-spin (accessed on 10 October 2020).

8. COAG Health Council. Australian National Breastfeeding Strategy: 2019 and Beyond. Available online: http://www. coaghealthcouncil.gov.au/Publications/Reports (accessed on 3 September 2020).

9. Australian Institute of Health and Welfare. 2010 Australian National Infant Feeding Survey: Indicator Results. Available online: https:/ / www.aihw.gov.au/reports / mothers-babies/2010-australian-national-infant-feeding-survey/summary (accessed on 7 July 2021).

10. Theurich, M.A. Perspective: Novel Commercial Packaging and Devices for Complementary Feeding. Adv. Nutr. 2018, 9, 581-589. [CrossRef]

11. Devenish, G.; Ytterstad, E.; Begley, A.; Do, L.; Scott, J. Intake, sources, and determinants of free sugars intake in Australian children aged 12-14 months. Matern. Child Nutr. 2018, 15, e12692. [CrossRef] [PubMed]

12. Dunford, E.; Louie, J.C.Y.; Byrne, R.; Walker, K.Z.; Flood, V.M. The Nutritional Profile of Baby and Toddler Food Products Sold in Australian Supermarkets. Matern. Child Health J. 2015, 19, 2598-2604. [CrossRef]

13. Theurich, M.A. Are Modern Complementary Food Packaging, Devices and Teats Compatible with International Guidance on Complementary Feeding? J. Hum. Lact. 2019, 36, 29-33. [CrossRef] [PubMed] 
14. IBISWorld. Baby Food Munufacturing in Australia. Available online: https://www.ibisworld.com/au/industry/baby-foodmanufacturing/5058/ (accessed on 10 September 2020).

15. Coxon, C.; Devenish, G.; Ha, D.; Do, L.; Scott, J.A. Sources and Determinants of Discretionary Food Intake in a Cohort of Australian Children Aged 12-14 Months. Int. J. Environ. Res. Public Health 2019, 17, 80. [CrossRef]

16. Qutteina, Y.; Hallez, L.; Mennes, N.; De Backer, C.; Smits, T. What Do Adolescents See on Social Media? A Diary Study of Food Marketing Images on Social Media. Front. Psychol. 2019, 10, 2637. [CrossRef] [PubMed]

17. Connor, S.M. Food-Related Advertising on Preschool Television: Building Brand Recognition in Young Viewers. Pediatrics 2006, 118, 1478-1485. [CrossRef] [PubMed]

18. Grummer-Strawn, L.M.; Holliday, F.; Jungo, K.T.; Rollins, N. Sponsorship of national and regional professional paediatrics associations by companies that make breast-milk substitutes: Evidence from a review of official websites. BMJ Open 2019, 9, e029035. [CrossRef] [PubMed]

19. Berry, N.J.; Gribble, K.D. Health and nutrition content claims on websites advertising infant formula available in Australia: A content analysis. Matern. Child Nutr. 2016, 13, 13. [CrossRef]

20. Abrahams, S.W. Milk and Social Media: Online Communities and the International Code of Marketing of Breast-milk Substitutes. J. Hum. Lact. 2012, 28, 400-406. [CrossRef] [PubMed]

21. Elliott, C.; Truman, E. Measuring the Power of Food Marketing to Children: A Review of Recent Literature. Curr. Nutr. Rep. 2019, 8, 323-332. [CrossRef] [PubMed]

22. Truman, E.; Elliott, C. Identifying food marketing to teenagers: A scoping review. Int. J. Behav. Nutr. Phys. Act. 2019, 16, 67. [CrossRef] [PubMed]

23. Hastings, G.; Angus, K.; Eadie, D.; Hunt, K. Selling second best: How infant formula marketing works. Glob. Health 2020, 16, 1-12. [CrossRef]

24. Tran, T.P. Personalized ads on Facebook: An effective marketing tool for online marketers. J. Retail. Consum. Serv. 2017, 39, 230-242. [CrossRef]

25. Correl, D. Social Media Statistics Australia September 2020. Available online: https:/ /www.socialmedianews.com.au/socialmedia-statistics-australia-september-2020/ (accessed on 31 October 2020).

26. Alianmoghaddam, N.; Phibbs, S.; Benn, C. "I did a lot of Googling": A qualitative study of exclusive breastfeeding support through social media. Women Birth 2019, 32, 147-156. [CrossRef]

27. Adamo, K.B.; Brett, K.E. Parental Perceptions and Childhood Dietary Quality. Matern. Child Health J. 2013, 18, 978-995. [CrossRef] [PubMed]

28. Begley, A.; Ringrose, K.; Giglia, R.; Scott, J. Mothers' Understanding of Infant Feeding Guidelines and Their Associated Practices: A Qualitative Analysis. Int. J. Environ. Res. Public Health 2019, 16, 1141. [CrossRef] [PubMed]

29. Walsh, A.; Kearney, L.; Dennis, N. Factors influencing first-time mothers' introduction of complementary foods: A qualitative exploration. BMC Public Health 2015, 15, 939. [CrossRef]

30. Smith, J.P.S.G.M.; Mehta, K.; James, J.; Berry, N.J.; Koh, C.; Salmon, L.; Blake, M. A Rapid Evidence Assessment: Does Marketing of Commercially Available Complementary Foods Affect Infant and Young Child Feeding? Australian National University: Canberra, Australia, 2015.

31. Manganello, J.A.; Smith, K.C.; Sudakow, K.; Summers, A.C. A content analysis of food advertisements appearing in parenting magazines. Public Health Nutr. 2013, 16, 2188-2196. [CrossRef] [PubMed]

32. Chen, Y.-C.; Chang, J.-S.; Gong, Y.-T. A Content Analysis of Infant and Toddler Food Advertisements in Taiwanese Popular Pregnancy and Early Parenting Magazines. J. Hum. Lact. 2015, 31, 458-466. [CrossRef] [PubMed]

33. Harris, J.L.; Pomeranz, J.L. Infant formula and toddler milk marketing: Opportunities to address harmful practices and improve young children's diets. Nutr. Rev. 2020, 78, 866-883. [CrossRef]

34. Mejia, P.S.L.; Gardin, K.; Nixon, L. Mother and Child Promotion: A Preliminary Analysis of Social Media Marketing of Infant Formula; Berkeley Media Studies Group: Berkeley, CA, USA, 2016.

35. Dattilo, A.M.; Carvalho, R.S.; Feferbaum, R.; Forsyth, S.; Zhao, A. Hidden Realities of Infant Feeding: Systematic Review of Qualitative Findings from Parents. Behav. Sci. 2020, 10, 83. [CrossRef]

36. Moumin, N.A.; Green, T.J.; Golley, R.K.; Netting, M.J. Are the nutrient and textural properties of Australian commercial infant and toddler foods consistent with infant feeding advice? Br. J. Nutr. 2020, 124, 754-760. [CrossRef]

37. D'Auria, E.; Borsani, B.; Pendezza, E.; Bosetti, A.; Paradiso, L.; Zuccotti, G.V.; Verduci, E. Complementary Feeding: Pitfalls for Health Outcomes. Int. J. Environ. Res. Public Health 2020, 17, 7931. [CrossRef]

38. Romo-Palafox, M.J.; Pomeranz, J.L.; Harris, J.L. Infant Formula and Toddler Milk Marketing and Caregiver's Provision to Young Children. Matern. Child Nutr. 2020, 16, e12962. [CrossRef] [PubMed]

39. Berry, N.J.; Jones, S.; Iverson, D.C. Toddler Milk Advertising in Australia: Infant Formula Advertising in Disguise? Australas. Mark. J. 2012, 20, 24-27. [CrossRef]

40. Cattaneo, A.; Pani, P.; Carletti, C.; Guidetti, M.; Mutti, V.; Guidetti, C.; Alessandra Alessandra Knowles1 on behalf of the Follow-on Formula Research Group. Advertisements of follow-on formula and their perception by pregnant women and mothers in Italy. Arch. Dis. Child. 2015, 100, 323-328. [CrossRef]

41. Montgomery, K.C.; Chester, J.; Grier, S.A.; Dorfman, L. The New Threat of Digital Marketing. Pediatr. Clin. N. Am. 2012, 59, 659-675. [CrossRef] 
42. Freeman, B.; Kelly, B.; Baur, L.; Chapman, K.; Chapman, S.; Gill, T.; King, L. Digital Junk: Food and Beverage Marketing on Facebook. Am. J. Public Health 2014, 104, e56-e64. [CrossRef] [PubMed]

43. Stanton, J.V.; Guion, D.T. Taking Advantage of a Vulnerable Group? Emotional Cues in Ads Targeting Parents. J. Consum. Aff. 2013, 47, 485-517. [CrossRef] 